\title{
Control of articular synovitis for bone and cartilage regeneration in rheumatoid arthritis
}

\author{
Hiromu Ito ${ }^{1 *}$, Furu Moritoshi ${ }^{1}$, Motomu Hashimoto ${ }^{2}$, Masao Tanaka $^{2}$ and Shuichi Matsuda ${ }^{1}$
}

\begin{abstract}
Background: Rheumatoid arthritis is an autoimmune inflammatory disease, the specific feature of which is progressive joint destruction induced by synovitis. The universal consensus is that alleviation of the synovitis is essential to prevent joint destruction and achieve clinical remission.

Main text: We have shown that not only achieving but also maintaining remission is crucial to prevent the progression of joint destruction. Although regeneration of the damaged joints is considered very rare, accumulating evidence shows that it actually occurs in routine clinical practice as a result of strong inhibition of synovitis using highly potent medications. Oral and intravenous medications affect the whole body, but to promote joint regeneration in a particular joint, two potent options are intra-articular steroid injection and synovectomy.

Conclusion: In situations where strong inhibition of synovitis combined with self-regeneration cannot repair severe joint destruction, regenerative medicine may in the future play a crucial role in the regeneration of damaged joints.
\end{abstract}

Keywords: Rheumatoid arthritis, Joint destruction, Synovitis, Articular cartilage, Regeneration

\section{Background}

RA pathology: joint destruction and synovitis

Rheumatoid arthritis (RA) is characterized by spontaneous progressive joint destruction that is predominantly caused by persistent, chronic synovitis in the joint [1]. Treatment with disease-modifying anti-rheumatic drugs (DMARDs) improves RA disease activities, but even with the best currently available treatment, residual disease activity can induce inflammatory joint damage such as erosion and joint-space narrowing that can be progressive and irreversible and that results in functional impairment [2-4].

The loss of the articular cartilage in RA is evident on $\mathrm{X}$-ray as joint-space narrowing, but in most cases, erosion and joint-space narrowing progress coordinately. Therefore, most studies show combined data for erosion and joint-space narrowing as exemplified by one of the most widely used joint destruction scores, the modified total Sharp score [5-7]. Moreover, although they do not

\footnotetext{
* Correspondence: hiromu@kuhp.kyoto-u.ac.jp

${ }^{1}$ The Department of Orthopaedic Surgery, Kyoto University Graduate School

of Medicine, 54 Kawahara-cho, Shogoin, Sakyo, Kyoto 606-8507, Japan

Full list of author information is available at the end of the article
}

progress separately, it is considered that erosion and joint-space narrowing can affect one another. Because joint destruction is mostly irreversible and directly causes joint pain and functional disability, a key target of treatment is prevention of joint destruction, and it is a fundamental rule of treatment that results should be determined, at least partially, by how well the treatment can prevent joint destruction [8].

As indicated above, synovitis is a fundamental clinical and pathological feature of RA and is largely responsible for the disease-associated joint destruction. Therefore, the basic strategy of treatment is to inhibit or alleviate synovitis; numerous clinical and basic studies have shown that this can prevent joint destruction. Most studies, guidelines, and recommendations have suggested that prevention of joint destruction can be achieved by decreasing disease activity and maintaining this lower activity as remission $[9,10]$. Moreover, to suppress the progression of joint destruction, alleviation of synovitis should be achieved as early as possible within the (therapeutic) window of opportunity [11, 12]. 


\section{Clinical remission and joint destruction}

The main goal of RA treatment is to suppress disease activity as early in the disease process as possible, thereby achieving clinical remission and preventing radiographic damage and disability. Several sets of criteria to define clinical remission in RA have been proposed and applied, starting with the 1981 American College of Rheumatology (ACR) definition of remission [13], followed by the definition of remission as a disease activity score of less than 1.6 based on 44 joints (DAS44) [14], later modified to a score of less than 2.6 involving 28 joints (DAS28) [15], a clinical disease activity index (CDAI) of less than 2.8 [16], and a simplified disease activity index (SDAI) of less than 3.3 [17]. More recently, the ACR and the European League Against Rheumatism (EULAR) collaborated to propose that remission in RA can be defined either according to the remission criteria of both the CDAI and the SDAI or the new Boolean-based set of criteria (ACR/EULAR remission criterion) [18].

Treat to target (T2T) is considered a key strategy in the induction of remission in individual RA patients [19]. DAS28 remission is a feasible goal in daily clinical practice with the application of a T2T strategy of early and intensive treatment of patients with early RA, which leads to high remission rates [20] and limited radiographic progression after 1 year of follow-up [21]. However, clinical trials have demonstrated that some patients with RA in remission defined by DAS28 showed residual joint swelling and radiographic progression compared with patients in remission defined by ACR/ EULAR. However, the ACR/EULAR remission criteria are difficult to achieve in patients with established RA. It is unclear which criteria should be used and how often clinical remission can be achieved in daily clinical practice.

\section{Sustained clinical remission contributes to functional remission and less radiological progression}

On the basis of these considerations, we conducted a retrospective longitudinal study to investigate whether sustained clinical remission would reduce functional disability and radiological progression, to identify which remission criteria best reflected functional and radiological remission, and how often clinical remission should be achieved in daily clinical practice. The results of this study were partially described in an article in the official journal of the Japanese Orthopaedic Association [22].

\section{Materials and methods}

In 2012, we enrolled 384 patients from the Kyoto University Rheumatoid Arthritis Management Alliance (KURAMA) cohort [23], and complete datasets for 170 of these patients, with both more than 6 months of follow-up and with more than three visits during follow- up, were used in this study. The data collected included age, sex, disease duration, Steinbrocker class, Steinbrocker stage, swollen joint count based on assessment of 28 joints (SJC28), tender joint count based on assessment of 28 joints (TJC28), the presence of rheumatoid factor (RF) and/or anti-citrullinated protein antibodies, C-reactive protein level, erythrocyte sedimentation rate (ESR), score on the Health Assessment Questionnaire disability index (HAQ-DI) [24], the patient's assessment of pain measured using a $100-\mathrm{mm}$ visual analogue scale (VAS), and global assessments of disease activity by evaluators (EGA) and patients (PGA). The radiographs were scored according to the van der Heijde-modified Sharp scoring method by two trained physicians blinded to the sequence of the radiographs [6]. The change in the Sharp/van der Heijde score (SHS) during follow-up was the main outcome of the study and was divided by the years of follow-up to calculate the annual rate of change. Patients with more than 1 unit change in SHS per year were classified as "progressors" [25]. Patients with 5 or more unit change in SHS per year were classified as showing rapid radiographic progression (RRP). Four different remission criteria were evaluated in this study: DAS28-ESR calculated including ESR $(\mathrm{mm} / \mathrm{h}), \mathrm{TJC} 28, \mathrm{SJC} 28$, and the PGA. Remission was defined as reported previously [16, 17]. The rate of remission maintenance was calculated by dividing the length of time for each remission by the number of patient visits throughout the follow-up period. "Complete sustained remission" was defined as a maintenance rate of $100 \%$, "nearly sustained remission" was defined as a maintenance rate of $50 \%$ or more, "incomplete sustained remission" was defined as a maintenance rate of less than $50 \%$, and "no remission" was defined as a maintenance rate of $0 \%$.

\section{Results}

The demographic characteristics of the patients are shown in Table 1. Among the 170 patients, the mean (SD) maintenance rates of clinical remission were $38.4 \%$ (38.3\%) using DAS28, 23.0\% (31.5\%) using CDAI, 25.0\% (32.7\%) using SDAI, and 15.0\% (25.7\%) using Booleanbased remission criteria (Table 2). To determine whether biological DMARDs (bDMARDs) maintained clinical remission better than conventional synthetic DMARDs (csDMARDs), we compared the maintenance rates for each remission definition between the 62 patients treated with bDMARDs and the 108 patients treated with csDMARDs. The maintenance rate of remission defined according to DAS28-ESR was higher with bDMARDs than with csDMARDs (bDMARDs: mean 48.9\%, csDMARDs: mean $32.4 \% ; P<0.01)$. However, there were no significant differences between bDMARDs and csDMARDs in the maintenance rates of remission defined according to CDAI, SDAI, and Boolean-based criteria. Analysis of functional 
Table 1 Characteristics of the patient population

\begin{tabular}{|c|c|c|}
\hline & Mean \pm SD or $n$ (percent) & Median (range) \\
\hline Age, years & $62.7 \pm 12.4$ & $64.5(31 \sim 85)$ \\
\hline Disease duration, years & $13.6 \pm 11.5$ & $11.25(0.4 \sim 64.3)$ \\
\hline Women & 140 patients (82.4\%) & \\
\hline Steinbrocker's stage, I/II/III/IV & $23(13.5 \%) / 53(31.2 \%) / 27$ (15.9\%)/67 (39.4\%) & \\
\hline Steinbrocker's class, 1/2/3/4 & $41(24.1 \%) / 103(60.6 \%) / 25(14.7 \%) / 1(0.01 \%)$ & \\
\hline Rheumatoid factor positive & $133(78.2 \%)$ & \\
\hline Anti-citrullinated protein antibody positive & $135(79.4 \%)$ & \\
\hline C-reactive protein, mg/dl & $0.61 \pm 1.13$ & $0.1(0 \sim 5.4)$ \\
\hline Erythrocyte sedimentation rate, mm/h & $25.4 \pm 21.1$ & $18.5(0 \sim 117)$ \\
\hline Tender joint count, 0 to 28joints & $1.1 \pm 2.0$ & $0(0 \sim 14)$ \\
\hline Swollen joint count, 0 to 28joints & $1.2 \pm 1.7$ & $0(0 \sim 9)$ \\
\hline Patient's global assessment, 0 to $100 \mathrm{~mm}$ & $36.8 \pm 26.3$ & $32(1 \sim 100)$ \\
\hline Evaluator's global assessment, 0 to $100 \mathrm{~mm}$ & $14.6 \pm 15.1$ & $10(0 \sim 73)$ \\
\hline Disease activity score in 28 joints at endpoint & $3.05 \pm 1.22$ & $2.94(0.00 \sim 5.90)$ \\
\hline Simplified disease activity index at endpoint & $7.99 \pm 6.51$ & $5.90(0.20 \sim 30.40)$ \\
\hline Clinical disease activity index at endpoint & $7.37 \pm 5.97$ & $5.75(0.20 \sim 28.00)$ \\
\hline Health Assessment Questionnaire disability index, 0 to 3 & $0.90 \pm 0.76$ & $0.8125(0 \sim 3)$ \\
\hline Sharp/van der Heijde score at baseline & $109.5 \pm 101.1$ & $77.5(1 \sim 398)$ \\
\hline Sharp/van der Heijde score at endpoint & $112.7 \pm 101.6$ & $79.5(2 \sim 401)$ \\
\hline Annual change of Sharp/van der Heijde score & $3.6 \pm 7.9$ & $1(-8 \sim 58)$ \\
\hline Use of glucocorticoid & $76(44.7 \%)$ & \\
\hline Use of methotrexate & $141(70.6 \%)$ & \\
\hline Use of biologics & $62(36.5 \%)$ & \\
\hline TNF inhibitors & $40(23.5 \%)$ & \\
\hline Tocilizumab & $12(7.1 \%)$ & \\
\hline Abatacept & $10(5.9 \%)$ & \\
\hline
\end{tabular}

Data representing the demographic characteristics of the 170 patients. Data are presented as means \pm S.D. or $n$ (percent) and median (range)

impairment represented by HAQ-DI indicated that sustained clinical remission contributed to functional remission of RA (Table 3). The radiographic progression rates of patients as assessed by DAS28-ESR, SDAI, CDAI, and Boolean-based remission criteria are illustrated in Table 4. The annual change in SHS and a cumulative probability plot showing the individual data for all patients are presented in Figs. 1, 2, 3, and 4. There were fewer radiological progressors in the complete sustained remission and nearly sustained remission groups than in the incomplete sustained remission and no remission groups, for all definitions of remission. The number of progressors was

Table 2 Proportions of patients who sustained clinical remission according to each criterion during follow-up period

\begin{tabular}{|c|c|c|c|c|}
\hline & DAS28-ESR & CDAl & SDAl & Boolean-based \\
\hline Mean (SD) maintain rate of remission, \% & $38.4(38.3)$ & $23.0(31.5)$ & $25.0(32.7)$ & $15.0(25.7)$ \\
\hline No. (\%) of complete sustained remission & $26(15.3)$ & $9(5.3)$ & $12(7.1)$ & $4(2.4)$ \\
\hline No. (\%) of nearly sustained remission & $39(22.9)$ & $29(17.1)$ & $27(15.9)$ & $18(10.6)$ \\
\hline No. (\%) of incomplete sustained remission & $43(25.3)$ & $42(24.7)$ & $47(27.6)$ & $36(21.2)$ \\
\hline No. (\%) of none remission & $62(36.5)$ & $90(52.9)$ & $84(49.4)$ & $112(65.9)$ \\
\hline
\end{tabular}

Data represent the proportions of RA patients who sustained clinical remission according to each criterion during follow-up period. Complete sustained remission was defined as maintain rate of $100 \%$. Nearly sustained remission was defined as maintain rate of $50 \%$ or more. Incomplete sustained remission was defined as maintain rate of less than $50 \%$. None remission was defined as maintain rate of $0 \%$. Boolean-based is one of the ACR/EULAR remission criteria DAS28-ESR disease activity score based on 28 joint count and erythrocyte segmentation rate, CDAl clinical disease activity index, SDAl simplified disease activity index 
Table 3 Functional disability of patients who sustained clinical remission according to each criterion during follow-up period

\begin{tabular}{|c|c|c|c|c|c|}
\hline & & DAS28-ESR & CDAl & SDAl & Boolean-based \\
\hline Complete sustained remission & $\begin{array}{l}\text { Mean (SD) HAQ-DI } \\
\text { No. (\%) of functional remission }\end{array}$ & $\begin{array}{l}0.37(0.14) \\
20(76.9)\end{array}$ & $\begin{array}{l}0.36(0.25) \\
7(77.8)\end{array}$ & $\begin{array}{l}0.43(0.22) \\
9(75.0)\end{array}$ & $\begin{array}{l}0.22(0.38) \\
4(100)\end{array}$ \\
\hline Nearly sustained remission & $\begin{array}{l}\text { Mean (SD) HAQ-DI } \\
\text { No. (\%) of functional remission }\end{array}$ & $\begin{array}{l}0.65(0.12) \\
22(56.4)\end{array}$ & $\begin{array}{l}0.30(0.13) \\
25(86.2)\end{array}$ & $\begin{array}{l}0.33(0.14) \\
22(81.5)\end{array}$ & $\begin{array}{l}0.39(0.18) \\
14(77.8)\end{array}$ \\
\hline Incomplete sustained remission & $\begin{array}{l}\text { Mean (SD) HAQ-DI } \\
\text { No. (\%) of functional remission }\end{array}$ & $\begin{array}{l}0.93(0.12) \\
15(34.9)\end{array}$ & $\begin{array}{l}0.70(0.12) \\
18(42.9)\end{array}$ & $\begin{array}{l}0.71(0.11) \\
21(44.7)\end{array}$ & $\begin{array}{l}0.43(0.12) \\
23(63.9)\end{array}$ \\
\hline None remission & $\begin{array}{l}\text { Mean (SD) HAQ-DI } \\
\text { No. (\%) of functional remission }\end{array}$ & $\begin{array}{l}1.26(0.09) \\
14(22.6)\end{array}$ & $\begin{array}{l}1.24(0.07) \\
21(23.3)\end{array}$ & $\begin{array}{l}1.26(0.07) \\
19(22.6)\end{array}$ & $\begin{array}{l}1.15(0.06) \\
30(26.8)\end{array}$ \\
\hline
\end{tabular}

Functional disability was assessed by HAQ-DI at endpoint. Complete sustained remission was defined as maintain rate of $100 \%$. Nearly sustained remission was defined as maintain rate of $50 \%$ and more. Incomplete sustained remission was defined as maintain rate of less than $50 \%$. None remission was defined as maintain rate of $0 \%$. Functional remission was defined as $\mathrm{HAQ}-\mathrm{DI}<0.5$

$H A Q-D I$ health assessment questionnaire disability index

approximately equivalent in the complete and nearly sustained remission groups as assessed by all criteria, although no patients in either the complete or nearly sustained remission groups assessed by either SDAI or Boolean-based criteria were classified as RRP. To determine whether biological bDMARDs reduced radiological progression better than csDMARDs, we compared the annual change in SHS in the 62 patients treated with bDMARDs and the 108 patients treated with csDMARDs (Fig. 5). No instance of RRP was observed for patients treated with either bDMARDs or csDMARDs in the complete and nearly sustained remission groups as defined by the SDAI criteria. However, RRP was observed with both treatments in the groups with incomplete sustained or no remission defined by the SDAI criteria.

In conclusion, this study clearly demonstrated that sustained clinical remission contributes to reduced radiological progression in RA.

\section{Bone and cartilage regeneration in rheumatology clinical practice}

The results described above clearly show that not only achieving remission but also maintaining remission is crucial for preventing joint destruction. However, is it possible to achieve bone regeneration using any type of treatment? And if so, how?

Historically, it was the universal consensus in clinical rheumatology that joint destruction could not be reversed by any kind of treatment. In other words, once any part of the joint was destroyed, nothing could be done for the joint other than trying to prevent further destruction. This was the main reason why practitioners were eager to start aggressive treatment before any joint destruction was observed. This concept still holds mostly true in the current medical situation. However, even before the advent of highly effective treatments such as bDMARDs and targeted synthetic DMARDs (tsDMARDs), bone regeneration or healing was observed in a small proportion

Table 4 Radiographic progression of patients who sustained clinical remission according to each criterion during follow-up period

\begin{tabular}{|c|c|c|c|c|c|c|}
\hline & & & DAS28-ESR & CDAl & SDAl & Boolean-based \\
\hline \multirow[t]{3}{*}{ Complete sustained remission } & Annual change in SHS & Mean (SD) & $2.2(4.0)$ & $1.7(1.7)$ & $1.3(1.6)$ & $2.4(1.7)$ \\
\hline & & range & & & & \\
\hline & No. (percent) of RRP & & $2(7.7)$ & $0(0)$ & $0(0)$ & $0(0)$ \\
\hline \multirow[t]{3}{*}{ Nearly sustained remission } & Annual change in SHS & Mean (SD) & $2.7(8.7)$ & $1.7(2.5)$ & $1.6(1.5)$ & $1.3(1.5)$ \\
\hline & & range & $-8-52$ & & & \\
\hline & No. (percent) of RRP & & $3(7.7)$ & $1(3.4)$ & $0(0)$ & $0(0)$ \\
\hline \multirow[t]{3}{*}{ Incomplete sustained remission } & Annual change in SHS & Mean (SD) & $2.7(3.9)$ & $2.3(8.2)$ & $3.5(8.6)$ & $3.2(9.0)$ \\
\hline & & range & & $-8-52$ & $-8-52$ & $-2-52$ \\
\hline & No. (percent) of RRP & & $9(20.9)$ & $4(9.5)$ & $9(19.1)$ & $3(8.3)$ \\
\hline \multirow[t]{3}{*}{ None remission } & Annual change in SHS & Mean (SD) & $5.5(10.3)$ & $5.1(9.1)$ & $4.8(9.1)$ & $4.2(8.3)$ \\
\hline & & range & & & & \\
\hline & No. (percent) of RRP & & $20(32.3)$ & $29(32.2)$ & $25(29.8)$ & $31(27.7)$ \\
\hline
\end{tabular}

Radiographic progression was assessed by annual change in Sharp/van der Heijde score (SHS) during follow-up period. RRP (rapid radiographic progression) was defined as 5 or more unit change in SHS per year. Complete sustained remission was defined as maintain rate of $100 \%$. Nearly sustained remission was defined as maintain rate of $50 \%$ and more. Incomplete sustained remission was defined as maintain rate of less than $50 \%$. None remission was defined as maintain rate of $0 \%$ 

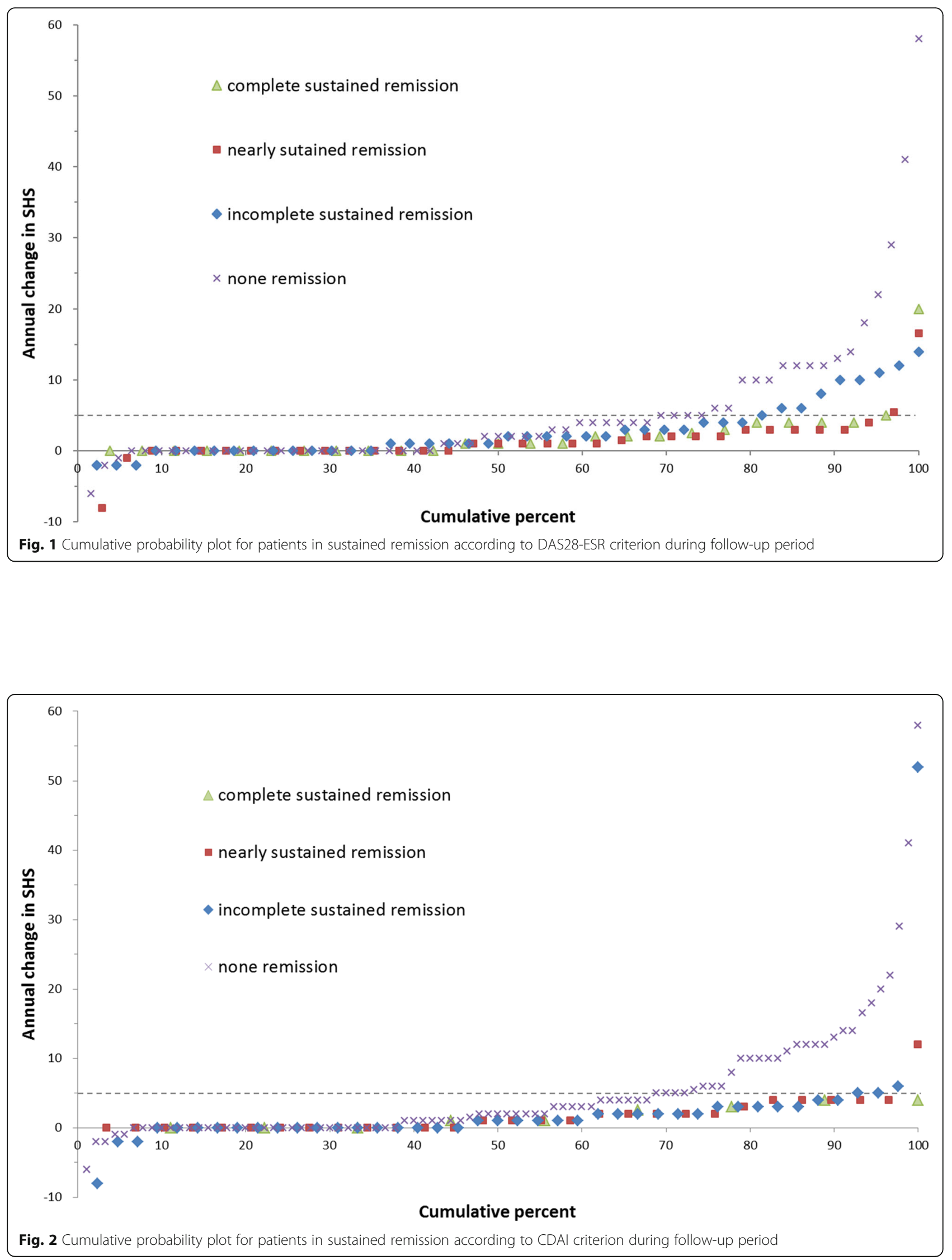

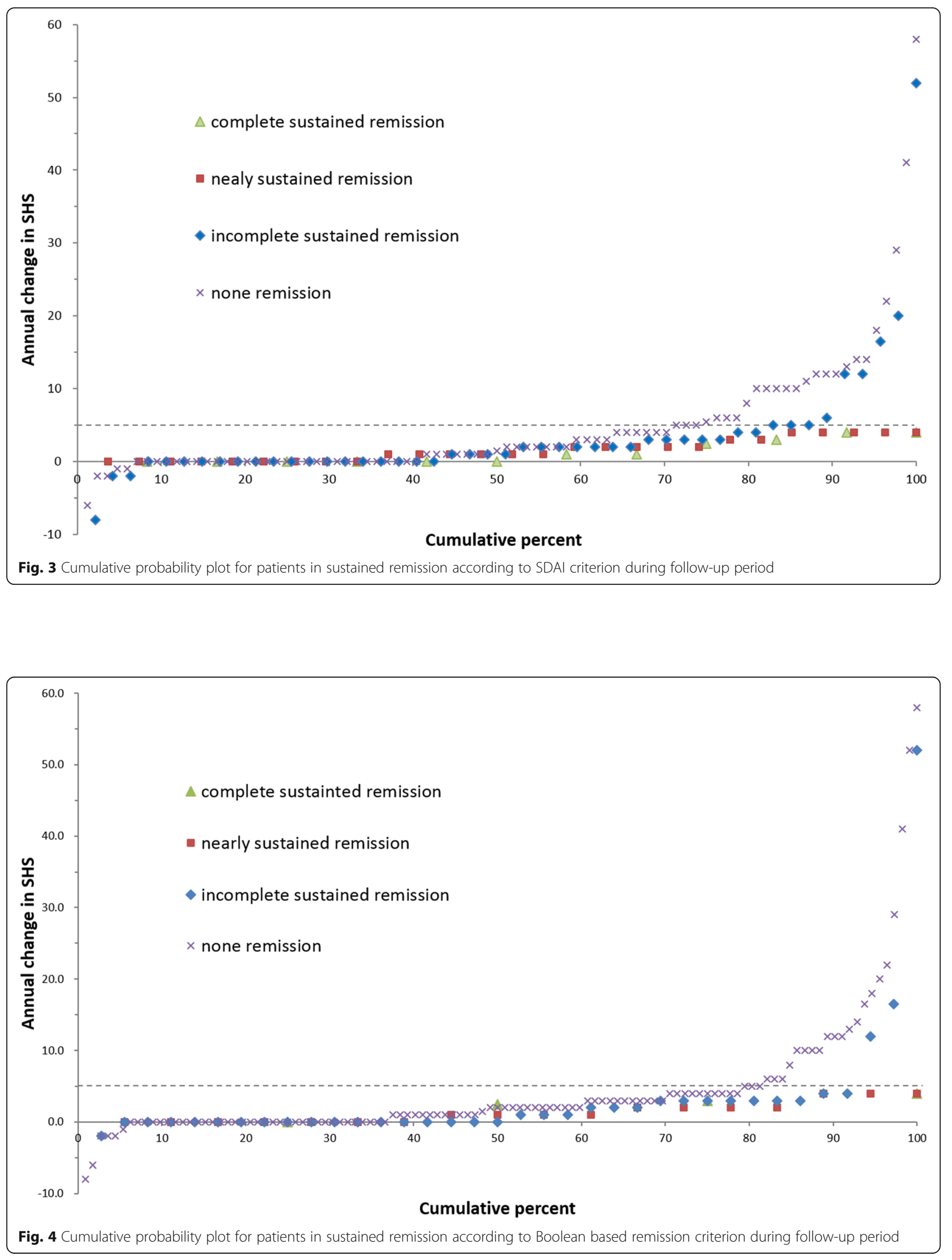


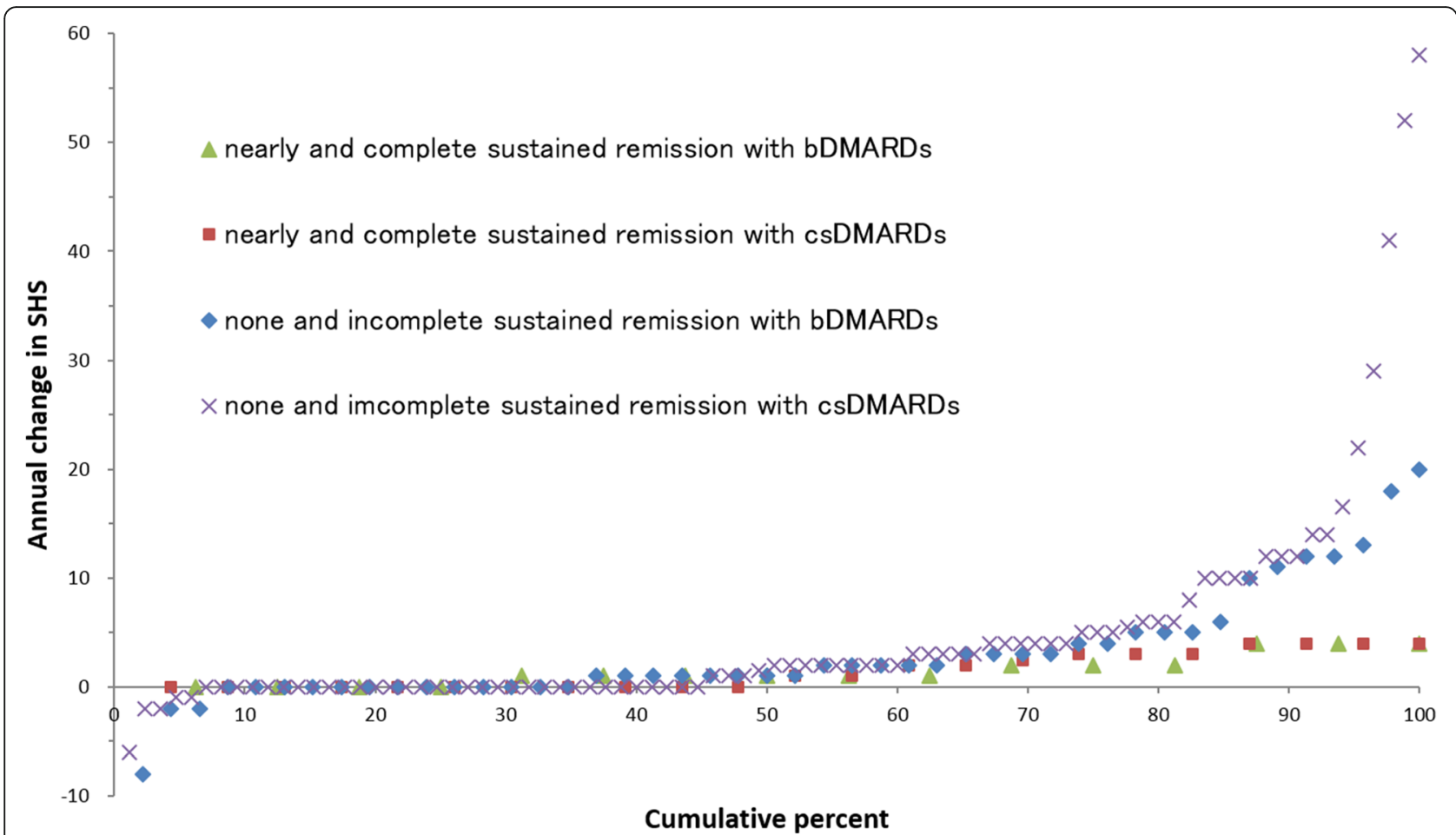

Fig. 5 Cumulative probability plot for patients in sustained remission according to SDAI criterion during follow-up period compared bDMARDs with CSDMARDs

of RA patients. In a pioneering case report, Rau and Herborn described the healing of erosive changes in six RA patients who were treated with methotrexate and/or gold sodium thiomalate (GST) [26]. Although Rau and colleagues repeatedly reported such cases, it was still considered that such healing was very rare [26-28].

However, the dramatic results of treatment with bDMARDs have gradually changed the entire basis of the treatment strategy for RA and practitioners' frame of mind in terms of bone destruction and regeneration. The 2005 article by Ikari and Momohara clearly showed that methotrexate can induce bone regeneration [29], and many practitioners have seen such cases repeatedly in their routine clinical practice. Indeed, some of the first randomized controlled studies using bDMARDs reported negative average values for joint destruction after a certain period of treatment [30-32], which means that the majority of patients who used bDMARDs experienced bone regeneration in one way or another.

However, critics or doubters claimed that such regeneration was seen only in small joints such as the proximal interphalangeal, metacarpophalangeal, or metatarsophalangeal joints in the fingers or toes. Indeed, most case reports have shown bone regeneration only of small joints. However, Momohara's case report clearly showed that even a large joint (hip joint) can achieve cartilage regeneration, or at least the reappearance of the joint space, with an effective treatment such as bDMARDs [33]. After this pioneering case report, clinical studies including a case series have described bone regeneration of large joints [34]. As a result, a Japanese research group has established a radiological change score called the ARASHI change score, which incorporates the improvements in bone quality, joint space narrowing, joint conformity, and the disappearance of bone erosion and joint surface destruction [35]. Unfortunately, it is still the case that joint regeneration in the large joints is relatively rare. Seki and Matsushita have shown that, once joint damage has been detected, damage in the ankle joint tends to be less progressive but joint destruction in the hip and knee joints is likely to progress even following a good response to anti-tumor necrosis factor alpha treatment [36-38]. Therefore, it remains largely unresolved whether a large joint can regenerate, and if so, how it regenerates. Other unresolved issues are the nature of the predictors of largejoint regeneration, and how we can intervene to stimulate regeneration or, at least, to prevent the progression of large-joint destruction.

\section{Is it possible to induce joint regeneration by surgical management?}

Most therapeutic strategies for prevention or regeneration of joint destruction are based on the use of effective medications. However, oral or intravenous medication has 
an effect on the whole body, i.e., it diffuses throughout the whole body and may therefore be less effective in a particular joint. One of the potent options for treating a particular joint is intra-articular injection. Indeed, several studies indicate that intra-articular injection of steroid is highly effective and comparable to bDMARDs for the alleviation of disease activity [39]. For example, a preliminary report showed that in osteoarthritis, intrajoint injection of bDMARDs can achieve a better response than injection of hyaluronan [40]. Moreover, a recent study showed that intra-articular glucocorticoids in combination with methotrexate can induce bone regeneration in some cases of RA, although this response is relatively rare [41]. Future investigations should determine which patients should receive intra-articular steroid injection and its optimal timing.

Another possible approach to this issue is surgical intervention. Joint regeneration, especially cartilage regeneration, has been widely investigated over the last three decades. We recently published a report of scaffoldless hyaline cartilaginous tissue derived from induced pluripotent stem cells [42]. However, despite committed, long-term efforts worldwide, clinically useful hyaline cartilage regeneration has not yet been achieved. To overcome this highly problematic threshold to achieving joint regeneration, the most plausible treatment strategy is to induce or assist the patient's own ability to regenerate bone and cartilage. In the case of inflammatory arthritis such as RA, the reduction of synovitis or the surgical removal of inflammatory synovia is one plausible option. We have experienced one such case in the past.

The patient, a 21-year-old woman, presented to our hospital with pain and a soft tissue mass on her left fifth metatarsophalangeal joint. Radiographic and magnetic resonance imaging showed a tumor-like mass with destruction of the joint (Fig. 6a', white arrow), which was reported as being suggestive of a benign tumor. At surgery, synovia-like tissues were observed that had migrated into the bare area of this joint. This lesion was successfully removed, and histological analysis confirmed synovitis, suspicious of RA. The patient gradually developed polyarticular synovitis, and methotrexate was started 3 years later. Surprisingly, bone repair of this joint was achieved 1 year after surgery and was maintained without recurrence of synovitis for more than 5 years (Fig. 6b', c', white arrows). In contrast, her left first metatarsophalangeal joint gradually developed destructive changes (Fig. 6a, b, white thick arrow), which led to surgical arthrodesis 3 years later (Fig. 6c, white thick arrow).

Some authors recommend surgical synovectomy for patients with RA who do not experience substantial pain relief in response to medications. By removing all synovial tissues, synovectomy can diminish local pain and swelling, but bone repair of damaged joints has not

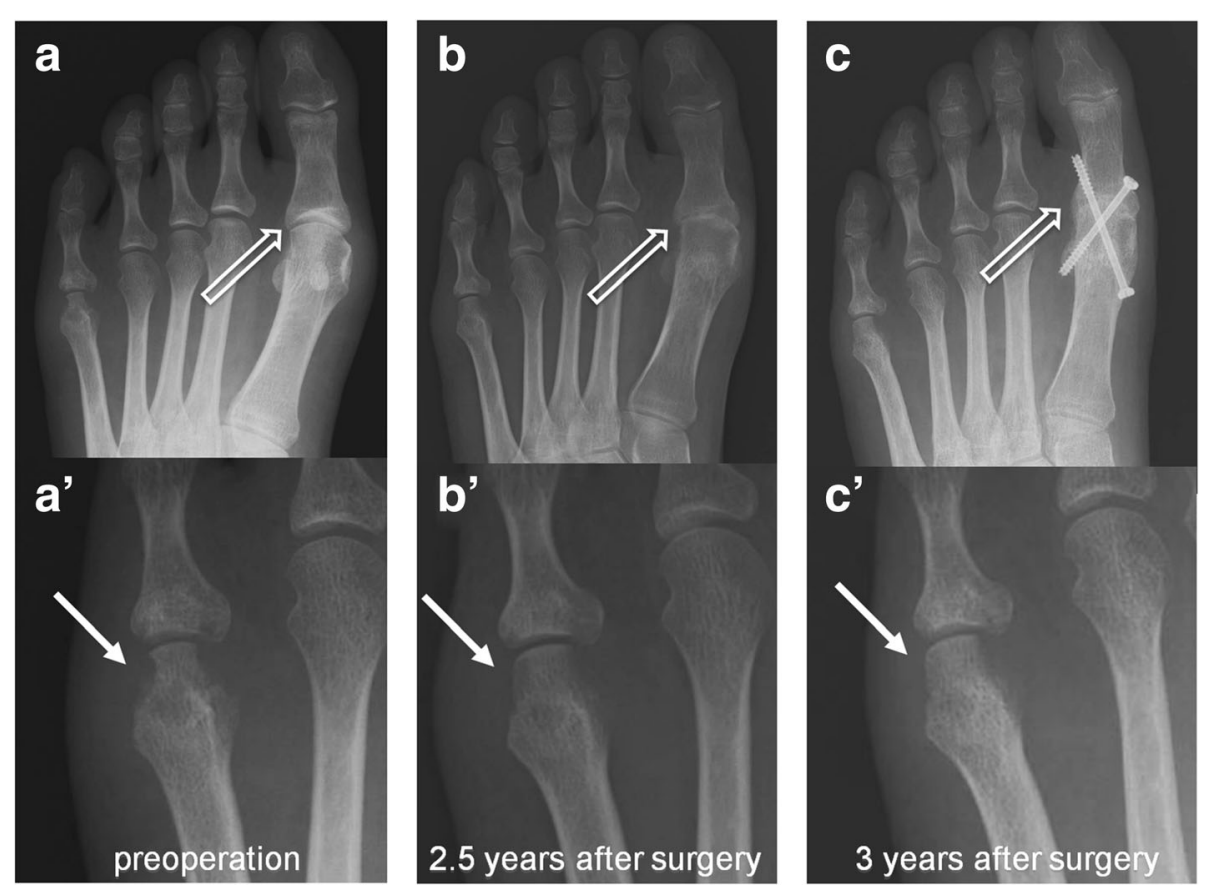

Fig. 6 a-c, $\mathbf{a}^{\prime}-\mathbf{c}^{\prime}$ Bone regeneration after synovectomy of the 5 th metatarsophalangeal joint of the left foot. The left panel shows the preoperative radiograph of the left foot. Bone erosion was seen in the 5 th metatarsal head. The middle panel shows the reappearance of the 5 th metatarsal head 2.5 years after synovectomy of the joint. Joint space narrowing appeared at the 1 st metatarsophalangeal joint. The right panel shows consolidation of the 5 th metatarsal head. The 1st metatarsophalangeal joint was fixed 
been expected. This case provides evidence that synovectomy can induce bone repair of a damaged joint in a patient with early RA. To the best of our knowledge, this is the very first report that synovectomy indeed stimulated joint regeneration. Pinder previously reported that synovectomy with drilling of areas of articular cartilage loss showed cartilage regeneration and relief of symptoms [43]. However, since then, no other report has shown similar results by any surgical procedures. The reason of his success may be that he probably conducted this procedure in patients with very low disease activity. But the regeneration potential of the joint should be paid with full attention even in RA patients in the current medication.

Also, the molecular mechanisms of how the regeneration occurs have been investigated and proposed, which has attracted huge attention from basic researchers. Several review articles recently summarized the proposed mechanism of bone remodeling in RA that proinflammatory cytokines such as TNF alpha stimulates the production of DKK-1 family and soluble frizzled related protein, suggesting that inhibition of such cytokines downregulates those proteins and revives bone formation processes [44, 45]. Wehmeyer et al. recently lay stress on the importance of stromal cells which release Wnt antagonists such as sclerostin and DKK-1 under inflammatory conditions $[44,46]$. Taken together, blocking proinflammatory cytokines or removal of synovial tissues producing such cytokines can regain the balance of bone resorption and formation and can stimulate bone regeneration. Adding to the suppression of proinflammatory cytokines or cells, suppression of Wnt antagonists or stromal cells may be a potent therapeutic option in the future.

\section{Future perspectives}

In inflammatory arthritis, synovitis causes bone and cartilage destruction as described above. One of the most crucial requirements for regeneration of the destroyed joint is alleviation of synovitis. This can be achieved by use of adequate medication as soon as possible after the diagnosis of the disease. When the joint has the ability to regenerate the destroyed bone and/or articular cartilage, self-regeneration should occur after alleviation of the synovitis. However, regenerative medicine will have a crucial role in treatment when this ability is lost, or when the destruction is too severe to be overcome. Although it is still uncertain what kind of treatment options will be available in routine clinical practice, regenerative medicine should be able to rescue the damaged joint using potent cell therapies.

\section{Conclusions}

To prevent joint destruction in inflammatory arthritis such as RA, the universal consensus is to treat, to alleviate synovitis and to achieve clinical remission. Our study shows that maintaining remission is also crucial to prevent the progression of joint destruction. Although regeneration of the damaged joint has been considered to occur very rarely, accumulating evidence shows that it can actually occur in routine clinical practice after strong inhibition of synovitis with highly potent medications. Two potent options other than oral or intravenous medication for inducing joint regeneration in a particular joint would be intra-articular steroid injection and synovectomy. In the future, regenerative medicine could play a crucial role in inducing regeneration of damaged joints after synovitis is effectively inhibited when selfregeneration cannot overcome severe destruction.

\section{Abbreviations \\ ACR: American College of Rheumatology; bDMARD: Biological DMARD; CDAl: Clinical disease activity index; CSDMARD: Conventional synthetic DMARD; DAS28: Disease activity score involving a 28 joints; DAS44: Disease activity score based on 44 joints; DMARD: Disease-modifying anti-rheumatic drug; EGA: Global assessments of disease activity by evaluators; ESR: Erythrocyte sedimentation rate; EULAR: The European League Against Rheumatism; HAQ- DI: The Health Assessment Questionnaire disability index; KURAMA: The Kyoto University Rheumatoid Arthritis Management Alliance; PGA: Global assessments of disease activity by patients; RA: Rheumatoid arthritis; RF: Rheumatoid factor; RRP: Rapid radiographic progression; SDAl: Simplified disease activity index; SHS: Sharp/van der Heijde score; SJC28: Swollen joint count based on assessment of 28 joints; T2T: Treat to target; TJC28: Tender joint count based on assessment of 28 joints; tsDMARD: Targeted synthetic DMARD; VAS: Visual analogue scale}

\section{Acknowledgements}

The authors thank Drs. Tsuneyo Mimori, Takao Fujii, Chicashi Terao, Noriyuki Yamakawa, Kohei Nishitani, Kosaku Murakami, and Hiroyuki Yoshitomi for their thoughtful discussion and technical assistance.

\section{Availability of data and materials}

The data and material are accessible by any parties through the corresponding author $(\mathrm{HI})$.

\section{Authors' contributions}

$\mathrm{HI}, \mathrm{MF}$, and SM contributed to the study conception and design. MF contributed to the analysis of the data. $\mathrm{HI}, \mathrm{MF}, \mathrm{MH}$, and MT contributed to the acquisition of data. $\mathrm{HI}$ and MF contributed to the interpretation of the data. HI and MF drafted the article. $\mathrm{HI}, \mathrm{MF}, \mathrm{MH}, \mathrm{MT}$, SM revised the article and gave final approval. All authors read and approved the final manuscript.

\section{Ethics approval and consent to participate}

Written informed consent for this study was obtained from all participating patients. This study was designed in accordance with the Helsinki declaration and was approved by the ethics committee of Kyoto University Graduate School and Faculty of Medicine (R0357).

Consent for publication

All of the listed authors declared the consent for publication.

\section{Competing interests}

The Department of Advanced Medicine for Rheumatic Diseases is supported by Nagahama City, Shiga, Japan, and four pharmaceutical companies (Mitsubishi Tanabe Pharma Co., Chugai Pharmaceutical Co. Ltd, UCB Japan Co. Ltd, and AYUMI Pharmaceutical Co.). KURAMA cohort study is supported by a grant from Daiichi Sankyo Co. Ltd. This study is conducted as investigator initiate study. HI has received a research grant and/or speaker fee from Bristol-Myers, Astellas, and Eli Lily. MH has received research grants from Astellas and Daiichi-Sankyo. MT has received research grants from Astellas, Abbvie, Pfizer, and Taisho-Toyama. MF and SM declared no conflicts of interest. The sponsors were not involved in the study design; in the collection, analysis, and interpretation of data; in the writing of this 
manuscript; or in the decision to submit the article for publication. The authors, their immediate families, and any research foundations with which they are affiliated have not received any financial payments or other benefits from any commercial entity related to the subject of this article.

\section{Publisher's Note}

Springer Nature remains neutral with regard to jurisdictional claims in published maps and institutional affiliations.

\section{Author details}

${ }^{1}$ The Department of Orthopaedic Surgery, Kyoto University Graduate School of Medicine, 54 Kawahara-cho, Shogoin, Sakyo, Kyoto 606-8507, Japan. ${ }^{2}$ The Department of Advanced Medicine for Rheumatic Diseases, Kyoto University Graduate School of Medicine, Kyoto, Japan.

Received: 8 January 2018 Accepted: 7 March 2018

Published online: 16 April 2018

\section{References}

1. Terao C, Hashimoto M, Yamamoto K, Murakami K, Ohmura K, Nakashima R, et al. Three groups in the 28 joints for rheumatoid arthritis synovitis-analysis using more than 17,000 assessments in the KURAMA database. PLoS One. 2013;8(3):e59341.

2. Keystone EC, Haraoui B, Guerette B, Mozaffarian N, Liu S, Kavanaugh A. Clinical, functional, and radiographic implications of time to treatment response in patients with early rheumatoid arthritis: a posthoc analysis of the PREMIER study. J Rheumatol. 2014;41(2):235-43.

3. Scott DL, Pugner K, Kaarela K, Doyle DV, Woolf A, Holmes J, et al. The links between joint damage and disability in rheumatoid arthritis. Rheumatology (Oxford). 2000:39:122-32.

4. Welsing PM, Van Gestel AM, Swinkels HL, Kiemeney LA, Van Riel PL. The relationship between disease activity, joint destruction, and functional capacity over the course of rheumatoid arthritis. Arthritis Rheum. 2001:44:2009-17.

5. Sharp JT, Young DY, Bluhm GB, Brook A, Brower AC, Corbett M, Decker JL, Genant HK, Gofton JP, Goodman N, et al. How many joints in the hands and wrists should be included in a score of radiologic abnormalities used to assess rheumatoid arthritis? Arthritis Rheum. 1985:28(12):1326-35.

6. van der Heijde D. How to read radiographs according to the Sharp/van der Heijde method. J Rheumatol. 1999;26(3):743-5.

7. van der Heijde D, Dankert T, Nieman F, Rau R, Boers M. Reliability and sensitivity to change of a simplification of the Sharp/van der Heijde radiological assessment in rheumatoid arthritis. Rheumatology (Oxford). 1999;38(10):941-7.

8. Smolen JS, Aletaha D, Redlich K. The pathogenesis of rheumatoid arthritis: new insights from old clinical data? Nat Rev Rheumatol. 2012:8(4):235-43.

9. Smolen JS, Landewé R, Bijlsma J, Burmester G, Chatzidionysiou K, Dougados M, Nam J, Ramiro S, Voshaar M, van Vollenhoven R, Aletaha D, Aringer M, Boers M, Buckley CD, Buttgereit F, Bykerk V, Cardiel M, Combe B, Cutolo M, van Eijk-Hustings Y, Emery P, Finckh A, Gabay C, Gomez-Reino J, Gossec L, Gottenberg JE, Hazes JMW, Huizinga T, Jani M, Karateev D, Kouloumas M, Kvien T, Li Z, Mariette X, McInnes I, Mysler E, Nash P, Pavelka K, Poór G, Richez C, van Riel P, Rubbert-Roth A, Saag K, da Silva J, Stamm T, Takeuchi T, Westhovens $R$, de Wit M, van der Heijde D. EULAR recommendations for the management of rheumatoid arthritis with synthetic and biological disease-modifying antirheumatic drugs: 2016 update. Ann Rheum Dis. 2017:76(6):960-77.

10. Singh JA, Saag KG, Bridges SL Jr, Akl EA, Bannuru RR, Sullivan MC, Vaysbrot E, McNaughton C, Osani M, Shmerling RH, Curtis JR, Furst DE, Parks D, Kavanaugh A, O'Dell J, King C, Leong A, Matteson EL, Schousboe JT, Drevlow B, Ginsberg S, Grober J, St Clair EW, Tindall E, Miller AS, McAlindon T, American College of Rheumatology. 2015 American College of Rheumatology guideline for the treatment of rheumatoid arthritis. Arthritis Care Res (Hoboken). 2016;68(1):1-25.

11. van Steenbergen HW, da Silva JAP, Huizinga TWJ, van der Helm-van Mil AHM. Preventing progression from arthralgia to arthritis: targeting the right patients. Nat Rev Rheumatol. 2018;14(1):32-41.

12. van Nies JA, Tsonaka R, Gaujoux-Viala C, Fautrel B, van der Helm-van Mil AH. Evaluating relationships between symptom duration and persistence of rheumatoid arthritis: does a window of opportunity exist? Results on the Leiden early arthritis clinic and ESPOIR cohorts. Ann Rheum Dis. 2015;74(5):806-12.

13. Pinals RS, Masi AT, Larsen RA. Preliminary criteria for clinical remission in rheumatoid arthritis. Arthritis Rheum. 1981;24:1308-15.
14. Van der Heijde DMFM, van ' $t$ Hof MA, van Riel PLCM, Theunisse LM, Lubberts EW, van Leeuwen MA, van Rijswijk MH, van de LBA P. Judging disease activity in clinical practice in rheumatoid arthritis: first step in the development of a disease activity score. Ann Rheum Dis. 1990:49:916-20.

15. Prevoo ML, van 't Hof MA, Kuper HH, van Leeuwen MA, van de Putte $L B$, van Riel PL. Modified disease activity scores that include twenty-eight-joint counts: development and validation in a prospective longitudinal study of patients with rheumatoid arthritis. Arthritis Rheum. 1995;38:44-8.

16. Aletaha D, Nell VP, Stamm T, et al. Acute phase reactants add little to composite disease activity indices for rheumatoid arthritis: validation of a clinical activity score. Arthritis Res Ther. 2005:7:R796-806.

17. Aletaha D, Smolen JS. The simplified disease activity index (SDAI) and clinical disease activity index (CDAI) to monitor patients in standard clinical care. Best Pract Res Clin Rheumatol. 2007;21:663-75.

18. Felson DT, Smolen JS, Wells G, et al. American College of Rheumatology/ European League against Rheumatism provisional definition of remission in rheumatoid arthritis for clinical trials. Ann Rheum Dis. 2011;70:404-13.

19. Smolen JS, Aletaha D, Bijlsma JW, Breedveld FC, Boumpas D, Burmester G, et al. Treating rheumatoid arthritis to target: recommendations of an international task force. Ann Rheum Dis. 2010;69:631-7.

20. Schipper LG, Vermeer M, Kuper HH, Hoekstra MO, Haagsma CJ, Broeder AA, et al. A tight control treatment strategy aiming for remission in early rheumatoid arthritis is more effective than usual care treatment in daily clinical practice: a study of two cohorts in the Dutch Rheumatoid Arthritis Monitoring registry. Ann Rheum Dis. 2012;71:845-50.

21. Vermeer M, Kuper HH, Hoekstra M, Haagsma CJ, Posthumus MD, Brus HL, et al. Implementation of a treat-to-target strategy in very early rheumatoid arthritis: results of the Dutch Rheumatoid Arthritis Monitoring remission induction cohort study. Arthritis Rheum. 2011;63:2865-72.

22. Ito $H$, Furu M, Matsuda $\mathrm{S}$. What affects joint destruction in rheumatoid arthritis -effect of sustained remission ratio and biological disease modifying anti-rheumatic drugs. J Jpn Orthop Assoc. 2018;92(5):(in press). [in the Japanese]

23. Furu M, Hashimoto $M$, Ito $H_{\text {, Fujii }}$, Terao C, Yamakawa $N$, Yoshitomi $H_{\text {, }}$ Ogino H, Ishikawa M, Matsuda S, Mimori T. Discordance and accordance between patient's and physician's assessments in rheumatoid arthritis. Scand J Rheumatol. 2014;43(4):291-5.

24. Fries JF, Spitz P, Kraines RG, Holman HR. Measurement of patient outcome in arthritis. Arthritis Rheum. 1980;23:137-45.

25. van der Heijde $D$, Landewé $R$, van Vollenhoven $R$, et al. Level of radiographic damage and radiographic progression are determinants of physical function: a longitudinal analysis of the TEMPO trial. Ann Rheum Dis. 2008:67:1267-70.

26. Rau R, Herborn G. Healing phenomena of erosive changes in rheumatoid arthritis patients undergoing disease-modifying antirheumatic drug therapy. Arthritis Rheum. 1996;39(1):162-8.

27. Rau R, Wassenberg S, Herborn G, Perschel WT, Freitag G. Identification of radiologic healing phenomena in patients with rheumatoid arthritis. J Rheumatol. 2001;28(12):2608-15.

28. Wassenberg S, Rau R. Radiographic healing with sustained clinical remission in a patient with rheumatoid arthritis receiving methotrexate monotherapy. Arthritis Rheum. 2002;46(10):2804-7.

29. Ikari K, Momohara S. Images in clinical medicine. Bone changes in rheumatoid arthritis. N Engl J Med. 2005;353:e13.

30. Sharp JT, Van Der Heijde D, Boers M, Boonen A, Bruynesteyn K, Emery P, Genant HK, Herborn G, Jurik A, Lassere M, McQueen F, Østergaard M, Peterfy C, Rau R, Strand V, Wassenberg S, Weissman B, Subcommittee on Healing of Erosions of the OMERACT Imaging Committee. Repair of erosions in rheumatoid arthritis does occur. Results from 2 studies by the OMERACT Subcommittee on Healing of Erosions. J Rheumatol. 2003;30(5):1102-7.

31. Lipsky PE, van der Heijde DM, St Clair EW, Furst DE, Breedveld FC, Kalden JR, Smolen JS, Weisman M, Emery P, Feldmann M, Harriman GR, Maini RN; AntiTumor Necrosis Factor Trial in Rheumatoid Arthritis with Concomitant Therapy Study Group. Infliximab and methotrexate in the treatment of rheumatoid arthritis. Anti-Tumor Necrosis Factor Trial in Rheumatoid Arthritis with Concomitant Therapy Study Group. N Engl J Med 2000;343(22):1594-1602.

32. Klareskog L, van der Heijde D, de Jager JP, Gough A, Kalden J, Malaise M, Martín Mola E, Pavelka K, Sany J, Settas L, Wajdula J, Pedersen R, Fatenejad S, Sanda M, TEMPO (Trial of Etanercept and Methotrexate with Radiographic Patient Outcomes) study investigators. Therapeutic effect of the combination of etanercept and methotrexate compared with each 
treatment alone in patients with rheumatoid arthritis: double-blind randomised controlled trial. Lancet. 2004;363(9410):675-81.

33. Momohara S, Tanaka E, Iwamoto T, Ikari K, Yamanaka H. Reparative radiological changes of a large joint after adalimumab for rheumatoid arthritis. Clin Rheumatol. 2011;30(4):591-2.

34. Kanbe K, Oh K, Chiba J, Inoue Y, Taguchi M, Yabuki A. Efficacy of golimumab for preventing large joint destruction in patients with rheumatoid arthritis as determined by the ARASHI score. Mod Rheumatol. 2017;27(6):938-45.

35. Kaneko A, Matsushita I, Kanbe K, Arai K, Kuga Y, Abe A, Matsumoto T, Nakagawa N, Nishida K. Development and validation of a new radiographic scoring system to evaluate bone and cartilage destruction and healing of large joints with rheumatoid arthritis: ARASHI (assessment of rheumatoid arthritis by scoring of large joint destruction and healing in radiographic imaging) study. Mod Rheumatol. 2013;23(6):1053-62

36. Seki E, Matsushita I, Sugiyama E, Taki H, Shinoda K, Hounoki H, Motomura H, Kimura T. Radiographic progression in weight-bearing joints of patients with rheumatoid arthritis after TNF-blocking therapies. Clin Rheumatol. 2009;28(4):453-60.

37. Matsushita I, Motomura H, Seki E, Kimura T. Radiographic changes and factors associated with subsequent progression of damage in weightbearing joints of patients with rheumatoid arthritis under TNF-blocking therapies-three-year observational study. Mod Rheumatol. 2017;27(4):570-5.

38. Nakajima A, Aoki Y, Sonobe M, Takahashi H, Saito M, Terayama K, Nakagawa K. Radiographic progression of large joint damage in patients with rheumatoid arthritis treated with biological disease-modifying antirheumatic drugs. Mod Rheumatol. 2016;26(4):517-21.

39. Axelsen MB, Eshed I, Hørslev-Petersen K, Stengaard-Pedersen K, Hetland ML, Møller J, Junker P, Pødenphant J, Schlemmer A, Ellingsen T, Ahlquist P, Lindegaard H, Linauskas A, Dam MY, Hansen I, Horn HC, Ammitzbøll CG, Jørgensen A, Krintel SB, Raun J, Krogh NS, Johansen JS, Østergaard M OPERA study group. A treat-to-target strategy with methotrexate and intraarticular triamcinolone with or without adalimumab effectively reduces MRI synovitis, osteitis and tenosynovitis and halts structural damage progression in early rheumatoid arthritis: results from the OPERA randomised controlled trial. Ann Rheum Dis. 2015;74(5):867-75.

40. Ohtori S, Orita S, Yamauchi K, Eguchi Y, Ochiai N, Kishida S, Kuniyoshi K, Aoki Y, Nakamura J, Ishikawa T, Miyagi M, Kamoda H, Suzuki M, Kubota G, Sakuma Y, Oikawa Y, Inage K, Sainoh T, Sato J, Shiga Y, Abe K, Fujimoto K, Kanamoto $H$, Toyone $T$, Inoue G, Takahashi K. Efficacy of direct injection of etanercept into knee joints for pain in moderate and severe knee osteoarthritis. Yonsei Med J. 2015;56(5):1379-83.

41. Hørslev-Petersen $K$, Hetland ML, Ørnbjerg LM, Junker P, Pødenphant J, Ellingsen $T$, Ahlquist $P$, Lindegaard $H$, Linauskas A, Schlemmer A, Dam MY, Hansen I, Lottenburger T, Ammitzbøll CG, Jørgensen A, Krintel SB, Raun J, Johansen JS, Østergaard M, Stengaard-Pedersen K, OPERA Study-Group. Clinical and radiographic outcome of a treat-to-target strategy using methotrexate and intra-articularglucocorticoids with or without adalimumab induction: a 2-year investigator-initiated, double-blinded, randomised, controlled trial (OPERA). Ann Rheum Dis. 2016:75(9):1645-53.

42. Yamashita A, Morioka M, Yahara Y, Okada M, Kobayashi T, Kuriyama S, Matsuda S, Tsumaki N. Generation of scaffoldless hyaline cartilaginous tissue from human iPSCs. Stem Cell Rep. 2015;4(3):404-18.

43. Pinder I. Synovectomy with drilling of the rheumatoid knee. Proc R Soc Med. 1974;67(2):107-9.

44. Favero M, Giusti A, Geusens P, Goldring SR, Lems W, Schett G, Bianchi G. OsteoRheumatology: a new discipline? RMD Open. 2015;1(Suppl 1):e000083.

45. Goldring SR. Differential mechanisms of de-regulated bone formation in rheumatoid arthritis and spondyloarthritis. Rheumatology (Oxford). 2016; 55(suppl 2):ii56-60

46. Wehmeyer C, Pap T, Buckley CD, Naylor AJ. The role of stromal cells in inflammatory bone loss. Clin Exp Immunol. 2017;189(1):1-11.

\section{Submit your next manuscript to BioMed Central and we will help you at every step:}

- We accept pre-submission inquiries

- Our selector tool helps you to find the most relevant journal

- We provide round the clock customer support

- Convenient online submission

- Thorough peer review

- Inclusion in PubMed and all major indexing services

- Maximum visibility for your research

Submit your manuscript at www.biomedcentral.com/submit
) Biomed Central 